\title{
Competencies for HR Professionals Who Deliver Outcomes
}

\author{
Dave Ulrich, David Kryscynski, Michael Ulrich and Wayne Brockbank
}

Wrudy (HRCS) sponsored by the Ross School at the University of Michigan and the RBL Group, along with 22 regional partners around the world, has empirically defined the competencies of HR professionals and shown how those competencies affect personal effectiveness and business performance. In this seventh (2016) round, we collected over 30,000 worldwide surveys rating the competencies and performance of more than 4,000 HR professionals from more than 1,500 organizational units. The results ${ }^{1}$ simultaneously build on insights from prior rounds and generate new insights for the HR. The findings are centered on five questions, each with an action item for an HR professional who wants to create more value:

1. What are the competencies of HR professionals?

2. What competencies do HR professionals require to be personally effective (i.e., to be invited "to the table")?

3. When engaged "at the table" (in business discussions), who should HR professionals represent and what competencies are required?

4. What competencies do HR professionals require to drive business results?

5. What is the relative importance of the competencies of HR professionals versus the activities of the HR department in driving business results?

\section{COMPETENCIES FOR HR PROFESSIONALS}

In collaboration with our regional HR partners, we examined 123 specific items of what HR professionals should be, know, or do. We performed scores of factor analyses on these items to determine consistent domains of HR competence. Exhibit 1 portrays the nine competencies we identified for HR professionals. Three of these competencies were core drivers (explained more below):

In collaboration with our regional HR partners, we examined 123 specific items of what HR professionals should be, know, or do. We performed scores of factor analyses on these items to determine consistent domains of HR competence.

$\square$ Strategic Positioner - able to position a business to win in its market.

$\square$ Credible Activist - able to build relationships of trust by having a proactive point of view.

- Paradox Navigator -able to manage tensions inherent to businesses (e.g., be both long and short term, be both top down and bottom up).

We also found three domains of HR competence that are organization enablers, helping position HR to deliver strategic value:

$\square$ Culture and Change Champion -able to make change happen and manage organizational culture. 
- Human Capital Curator -able to manage the flow of talent by developing people and leaders, driving individual performance, and building technical talent.

- Total Reward Steward - able to manage employee well-being through financial and nonfinancial rewards.

We found three other delivery enablers that focused on managing the tactical or foundational elements of HR:

- Technology and Media Integrator - able to use technology and social media to drive create high-performing organizations.

$\square$ Analytics Designer and Interpreter - able to use analytics to improve decision making.

- Compliance Manager - able to manage the processes related to compliance by following regulatory guidelines.

Each of these HR competencies is important for the performance of HR professionals. ${ }^{2}$
Action item: Recognize these nine domains required to be effective as an $H R$ professional.

Exhibit 2 shows the mean $(1=$ low to $5=$ high) scores for each of the nine HR competency domains by different respondent groups. The nine competence domains represent the rows and the five columns represent different respondent groups to the 360-degree exercise. The patterns among the nine competency domains are quite similar (see scores in each column).

As the data will show, HR professionals are seen by their raters (in column 1) as having more competence as Credible Activists (4.33/5) and Compliance Manager $(4.32 / 5)$, and less competence in Total Rewards Steward (3.88/5) and Technology and Media Integrator (3.92/5). This same pattern holds regardless of who is rating the HR professional (self-rating, column 2; supervisor rating, column $3 ; \mathrm{HR}$ associate rating, column 4; and non-HR associate

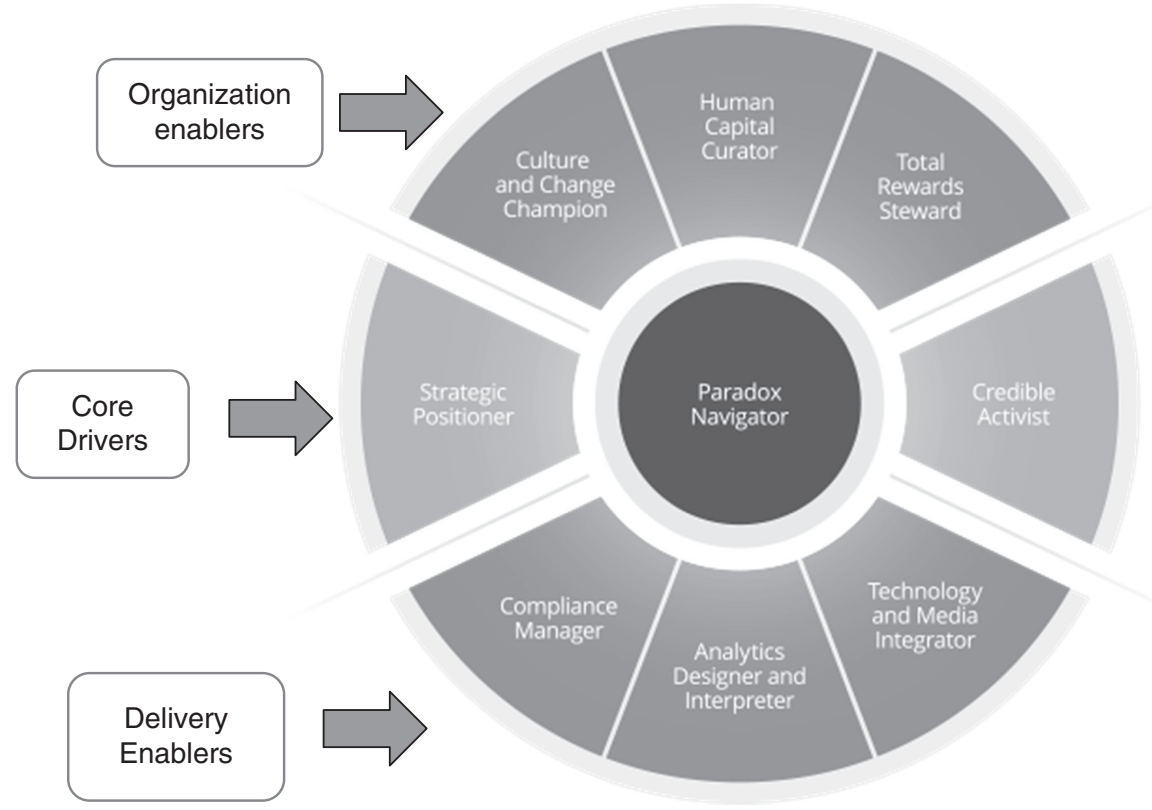

Exhibit 1. 2016 HR Competency Model: Round 7 


\begin{tabular}{|c|c|c|c|c|c|}
\hline & $\begin{array}{l}1 \\
\text { All Raters }\end{array}$ & $\begin{array}{l}2 \\
\text { Self- } \\
\text { Ratings }\end{array}$ & $\begin{array}{l}3 \\
\text { Supervisor } \\
\text { Ratings }\end{array}$ & $\begin{array}{l}4 \\
\text { HR } \\
\text { Associate } \\
\text { Ratings }\end{array}$ & $\begin{array}{l}5 \\
\text { Non-HR } \\
\text { Associate } \\
\text { Ratings }\end{array}$ \\
\hline Number of raters & 27,904 & 3,964 & 3,738 & 13,168 & 10,998 \\
\hline Strategic Positioner & 4.13 & 4.05 & 3.94 & 4.13 & 4.21 \\
\hline Credible Activist & 4.33 & 4.35 & 4.27 & 4.29 & 4.42 \\
\hline Paradox Navigator & 3.99 & 3.87 & 3.86 & 3.98 & 4.08 \\
\hline Culture and Change & & & & & \\
\hline Champion & 4.03 & 3.96 & 3.88 & 4.02 & 4.11 \\
\hline Human Capital Curator & 4.01 & 3.90 & 3.88 & 4.01 & 4.08 \\
\hline $\begin{array}{l}\text { Analytics Designer and } \\
\text { Interpreter }\end{array}$ & 4.01 & 3.89 & 3.78 & 4.04 & 4.06 \\
\hline Total Rewards Steward & 3.88 & 3.76 & 3.81 & 3.86 & 3.95 \\
\hline $\begin{array}{l}\text { Technology and Media } \\
\text { Integrator }\end{array}$ & 3.92 & 3.77 & 3.78 & 3.93 & 3.96 \\
\hline Compliance Manager & 4.32 & 4.34 & 4.31 & 4.30 & 4.38 \\
\hline Overall averages & 4.07 & 3.99 & 3.94 & 4.06 & 4.14 \\
\hline
\end{tabular}

Exhibit 2. Round 7 Competency Domain Averages by Rater Type

rating, column 5). These results make sense in that HR professionals have traditionally been known for their personal credibility and their compliance roles. We should note that we use 0.15 as a threshold for meaningful differences. ${ }^{3}$

The results by columns are quite interesting. HR professionals' selfassessments (column 2) are somewhat higher than supervisors' ratings (column

Supervisors who observe HR professionals doing their work may expect them to live up to higher expectations. HR associates see their $H R$ colleagues as having more skills than the HR professionals themselves, and non-HR associates have even higher ratings of HR professionals.

3), but lower than ratings by HR associates (column 4) and lower more than ratings by non-HR associates (column 5). Supervisors who observe HR professionals doing their work may expect them to live up to higher expectations. HR associates see their HR colleagues as having more skills than the HR professionals themselves, and non-HR associates have even higher ratings of HR professionals.

Perhaps HR professionals (column 2) recognize their limitations more than those who rate them; perhaps they have limited self-confidence in their own skills versus how others see them; or perhaps associate raters assume that HR professionals can do more. We tend toward the third explanation and see these findings as a license for HR professionals to do more in these nine competency domains. Their HR and non-HR associates already observe them as better than they rate themselves. HR professionals sometimes lament how they are perceived 
by their peers, but their self-image and selfconfidence may be a larger liability to their effectiveness.

\section{COMPETENCIES THAT HR PROFESSIONALS NEED TO BE PERSONALLY EFFECTIVE}

We measured the personal effectiveness of the 4,000 HR professionals (dependent variable) and looked at the nine HR competency domains (independent variables) to determine which HR competencies demonstrated the HR personal effectiveness that likely helps HR professionals get invited to business discussions. Although all nine competency domains affected HR's personal effectiveness, Credible Activist was by far the most important relative to the others (Exhibit 3). These results clearly indicate that HR's personal effectiveness is tied to being a Credible Activist.
Action item: To get invited "to the table" during business discussions, build relationships of trust and take a proactive stance on key issues.

\section{COMPETENCIES THAT HR PROFESSIONALS NEED TO SERVE STAKEHOLDERS}

When HR professionals are engaged in business discussions, they can choose to create value for different stakeholders. Traditionally, HR professionals are employee advocates, but today they also serve as line managers to deliver strategy and serve the business by creating value for external customers, investors, and the community.

Exhibit 4 shows that the necessary competencies for HR professionals vary depending on which parties they represent. Once they are invited to the business discussion (through individual effectiveness and being a Credible Activist), HR

\begin{tabular}{|l|l|}
\hline & $\begin{array}{l}\text { Percentage of Overall Personal } \\
\text { Effectiveness Explained by Each } \\
\text { Competency Domain } \\
\text { (adds up to 100\%) }\end{array}$ \\
\hline Strategic Positioner & 14.5 \\
\hline Credible Activist & 19.3 \\
\hline Paradox Navigator & 11.7 \\
\hline Culture and Change Champion & 14.2 \\
\hline Human Capital Curator & 13.1 \\
\hline Analytics Designer and Interpreter & 8.2 \\
\hline Total Rewards Steward & 6.2 \\
\hline Technology and Media Integrator & 4.9 \\
\hline Compliance Manager & 7.9 \\
\hline $\begin{array}{l}\text { Total percentage explained by } \\
\text { competencies }\end{array}$ & 83.4 \\
\hline
\end{tabular}

Exhibit 3. Independent Impact of Each HR Competency on Overall Individual Effectiveness 
professionals need to thoughtfully determine for whom they create value. If they want to create value for employees or line managers (internal stakeholders), they need to continue to be Credible Activists. But if they want to create value for customers and investors, they need to become Strategic Positioners. To create value for regulators, they also need skills as a Compliance Manager, which fits with our baseline expectations.
Traditionally, HR professionals are employee advocates, but today they also serve as line managers to deliver strategy and serve the business by creating value for external customers, investors, and the community.

Action item: When involved with business discussions, consider the stakeholders you serve and make sure you have the competence to deliver value to them.

\begin{tabular}{|c|c|c|c|c|c|c|}
\hline & \multicolumn{6}{|c|}{$\begin{array}{l}\text { Stakeholders Whom HR May Represent } \\
\text { (columns add to } 100 \% \text { ) }\end{array}$} \\
\hline & $\begin{array}{l}\text { External } \\
\text { Customers }\end{array}$ & $\begin{array}{l}\text { Investors/ } \\
\text { Owners }\end{array}$ & Communities & Regulators & $\begin{array}{l}\text { Line } \\
\text { Managers }\end{array}$ & Employees \\
\hline $\begin{array}{l}\text { Strategic } \\
\text { Positioner }\end{array}$ & 19.2 & 20.5 & 16.1 & 18.1 & 13.6 & 12.9 \\
\hline $\begin{array}{l}\text { Credible } \\
\text { Activist }\end{array}$ & 11.7 & 10.2 & 12.9 & 7.7 & 19 & 20.3 \\
\hline $\begin{array}{l}\text { Paradox } \\
\text { Navigator }\end{array}$ & 11.3 & 11.1 & 11.9 & 9.6 & 12 & 11.3 \\
\hline $\begin{array}{l}\text { Culture and } \\
\text { Change } \\
\text { Champion }\end{array}$ & 14.2 & 13.7 & 15.2 & 9.3 & 13.6 & 14.4 \\
\hline $\begin{array}{l}\text { Human } \\
\text { Capital } \\
\text { Curator }\end{array}$ & 12.5 & 13.1 & 12.5 & 9.2 & 14.9 & 12.2 \\
\hline $\begin{array}{l}\text { Analytics } \\
\text { Designer and } \\
\text { Interpreter }\end{array}$ & 10 & 11.4 & 7.6 & 12.8 & 8.4 & 6.8 \\
\hline $\begin{array}{l}\text { Total } \\
\text { Rewards } \\
\text { Steward }\end{array}$ & 7 & 6.4 & 10.2 & 8.8 & 5.3 & 8.3 \\
\hline $\begin{array}{l}\text { Technology } \\
\text { and Media } \\
\text { Integrator }\end{array}$ & 7.4 & 6.6 & 6.5 & 6.2 & 4.6 & 5.3 \\
\hline $\begin{array}{l}\text { Compliance } \\
\text { Manager }\end{array}$ & 6.7 & 7.1 & 7.2 & 18.3 & 8.5 & 8.5 \\
\hline $\begin{array}{l}\text { Percent of } \\
\text { value } \\
\text { explained by } \\
\text { all } \\
\text { competency } \\
\text { domains } \\
\text { together }\end{array}$ & 82.4 & 78.1 & 83.4 & 72.3 & 83.6 & 82.7 \\
\hline
\end{tabular}

Exhibit 4. Independent Impact of Each HR Competency on the Value Created for Stakeholders by HR Participant 


\section{THE HR COMPETENCIES THAT DRIVE BUSINESS RESULTS}

Finally, to determine what an HR professional should be, know, and do, we examined which HR competencies had the most impact on business performance (measured using a six-item scale assessing profitability, labor productivity, development of new products, customer satisfaction, attraction of new employees, and regulatory compliance). When we analyzed which of the nine competency domains most drove business results, we discovered that Paradox Navigator was the most important, followed closely by Strategic Positioner (see Exhibit 5).

Action item: To deliver business results, learn how to navigate paradoxes within your business.

\section{RELATIVE IMPORTANCE OF HR COMPETENCIES VERSUS HR ACTIVITIES IN DRIVING BUSINESS RESULTS}

The above-mentioned findings show what is required to be an effective HR professional. In this study, with over 1,500 businesses, we were also able to determine whether the competencies of the HR professionals or the quality of the HR department had more impact on business performance. As indicated in Exhibit 6, we found that HR department activities had twice the impact on business performance as had the competencies of the HR professionals. This research also found that the value created for stakeholders (employees, line managers, customers, investors, and communities) was three to five times more impacted by the HR department than by the competencies of HR professionals

\begin{tabular}{|l|l|}
\hline & $\begin{array}{l}\text { Overall Organizational Performance } \\
\text { Explained by Competency (total to 100\%) }\end{array}$ \\
\hline Strategic Positioner & 14.2 \\
\hline Credible Activist & 10.5 \\
\hline Paradox Navigator & 18.9 \\
\hline Culture and Change Champion & 10.9 \\
\hline Human Capital Curator & 9.0 \\
\hline Analytics Designer and Interpreter & 8.8 \\
\hline Total Rewards Steward & 8.4 \\
\hline Technology and Media Integrator & 12.5 \\
\hline Compliance Manager & 6.7 \\
\hline $\begin{array}{l}\text { Total percentage explained by } \\
\text { competencies }\end{array}$ & 7.7 \\
\hline
\end{tabular}

Exhibit 5. Independent Impact of Each HR Competency on the Perceived Organizational Unit's Performance 


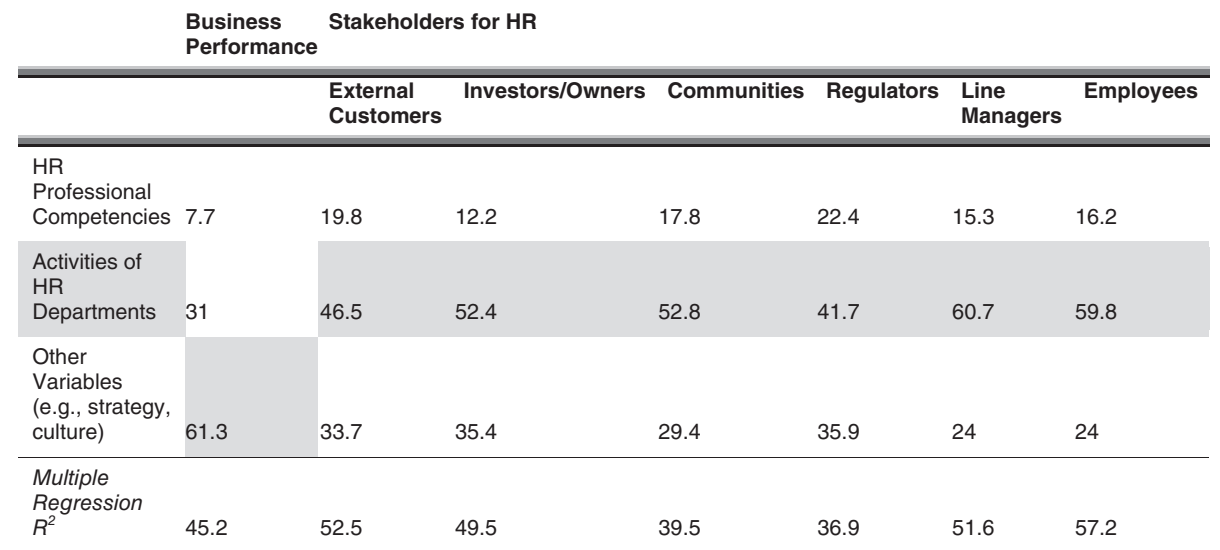

Exhibit 6. Percentage of Variance in the Value the HR Department Creates for Stakeholders Explained by Different Variable Groups (column totals 100\%)

themselves. Upgrading the HR professionals matters for business results, but upgrading the HR department matters even more.

Upgrading the HR professionals matters for business results, but upgrading the HR department matters even more.

Action item: Make sure that the HR department operates effectively and focuses on the right issues.

\section{CONCLUSION AND IMPLICATIONS}

In this research, we have identified what individual HR professionals should be, know, and do to deliver value. To get invited to business discussions, HR professionals need to be Credible Activists, who influence through relationships of trust. To serve customers and investors, HR professionals need to be Strategic Positioners, who understand business context and can think and act from the outside in. To deliver business value, HR professionals need to be Paradox Navigators, who effectively manage the inherent tensions in the business. In addition, we found that the old adage, "I like my HR professional, but I hate HR" needs to change, because the HR department's activities have more impact on all stakeholders than do individual HR professionals. We are confident that these findings and the subsequent implications for developing HR professionals and creating HR departments will enable $\mathrm{HR}$ to continue to add value.

\section{NOTES}

1. The study results are presented in more detail in Dave Ulrich et al., Victory through Organization (2017).

2. The authors have available statistics on these nine competency domains by gender, geography, respondents, time in $\mathrm{HR}$, and other demographics.

3. We are often asked about the "statistical significance" of these findings. With a sample of this size, almost all findings are "statistically" significant. We are more interested in "meaningfully significance," which implies that the information insights are worthy of attention. 
Dave Ulrich, University of Michigan/RBL Group (www.rbl.net), is coauthor of the new book Victory through Organization (2017). He is also the Rensis Likert Professor of Business at the Ross School, University of Michigan, and is a partner at the RBL Group, a consulting firm focused on helping organizations and leaders deliver value. He has consulted and done research with over half the Fortune 200 companies. He is the author or coauthor more than 30 books, including the number one Wall Street Journal business best seller The Why of Work, as well as Leadership Brand and $H R$ from the Outside In. He has been named a top management thought leader by BusinessWeek, Fortune, Financial Times, The Economist, and People Management, and is the recipient of many awards, including a Lifetime Achievement award from ASTD (now ATD). Known as the "father of modern human resources," Ulrich has been named repeatedly to the Thinkers 50 list of thought leaders and was designated the number one most influential international HR thought leader by HR Magazine. He serves on the board of directors for Herman Miller and the Board of Trustees of Southern Virginia University, and he has consulted for over half of the Fortune 200 companies. He may be contacted via e-mail at dou@umich.edu. David Kryscynski is an assistant professor of strategy at Brigham Young University's Marriott School of Management. He may be contacted via e-mail at dkryscyn@gmail.com. Mike Ulrich is assistant professor of business management at the Huntsman School of Business, Utah State University. He may be contacted via e-mail at mikedulrich@gmail.com. Wayne Brockbank is a clinical professor of business at the University of Michigan's Ross School of Business. He may be contacted atwbrock@umich.edu. 